\title{
Mucosal Immunity and the Intestinal Microbiome in the Development of Critical Illness
}

\author{
Krisztina Madách, ${ }^{1}$ Katalin Kristóf,, ${ }^{1,2}$ Eszter Tulassay, ${ }^{1}$ Zsolt Iványi, ${ }^{1}$ Anna Erdei, ${ }^{2,3}$ \\ András Király, ${ }^{4}$ János Gál, ${ }^{1}$ and Zsuzsa Bajtay ${ }^{2,3}$ \\ ${ }^{1}$ Department of Anaesthesiology and Intensive Therapy, Semmelweis University, Kútvölgyi Road 4, 1125 Budapest, Hungary \\ ${ }^{2}$ Department of Immunology, Eötvös Loránd University, Pázmány P. s. 1/C, 1117 Budapest, Hungary \\ ${ }^{3}$ Research Group of the Hungarian Academy of Sciences, Eötvös Loránd University, Pázmány P. s. 1/C, 1117 Budapest, Hungary \\ ${ }^{4}$ Department of Process Engineering, University of Pannonia, Egyetem Road 10, 8200 Veszprém, Hungary
}

Correspondence should be addressed to Katalin Kristóf, katalin.kristof@gmail.com

Received 31 August 2011; Accepted 26 September 2011

Academic Editors: A. Franco and C. Nicoletti

Copyright () 2011 Krisztina Madách et al. This is an open access article distributed under the Creative Commons Attribution License, which permits unrestricted use, distribution, and reproduction in any medium, provided the original work is properly cited.

\begin{abstract}
The intestinal community, including the commensal microbial flora as well as the host tissues, represents a functional whole in vivo. Under physiological circumstances, this symbiosis brings great benefit for the host; however, critical illness induces profound disturbances in the intestinal ecosystem affecting both procaryotic and eucaryotic members. Today, 25 years after the gut was first described as a motor of multiple organ dysfunction syndrome, the role of the injured splanchnic compartment in the pathomechanism and development of critical illness is still in the first line of research. Multiple mechanisms have been identified by which the stressed gut may affect host homeostasis, and how external intervention might help to rebalance physiology. This paper provides a brief overview of the present of this field.
\end{abstract}

\section{Introduction}

The gastrointestinal system represents an enormous surface to the internal world of the gut microbiome and nutrient antigens. Mucosal immunity faces the challenge to establish a balance between tolerance and immunity, elimination of pathogenic microbes and preservation of the crucial cooperation with normal flora members. Furthermore, commensal enteral bacteria share many epitopes with self-structures, making the situation even more complex, as revealed by recent investigations $[1,2]$. The intestinal microbiome, tightly interacting with the mucosal immune network, may be considered together as a special organ that has a clear impact on host physiology and pathology, including autoimmunity, atopic disorders, and even obesity [3-8]. The splanchnic immune apparatus also has an impact on host-pathogen interactions. B-1 lymphocyte-derived natural autoantibodies were shown to be involved in the first-line defence against pathogens, as well as in the early T-cell recruitment during initiation of delayed type hypersensitivity $(\mathrm{DTH})$ responses [1]. The intestinal modulation of host homeostasis becomes, however, even more obvious in critical illness (definitive or imminent organ failure).

The intestinal community with both eucaryotic and procaryotic members is partially separated from the systemic compartment and represents an unique symbiosis, which is recently being discovered in details. Since the majority of commensal species is not culturable under conventional circumstances [9], their exact nature yet remains obscure despite intensive research. Faced with the enormous amount of bacteria and nutrient antigens, the mucosal immune network consists of the intestinal epithelium, intraepithelial lymphocytes, and the immune apparatus of the lamina propria, Peyer's patches, and mesenteric lymph nodes. Lymphoid elements of the splanchnic immune system frequently belong to unconventional lymphocyte populations that possess a restricted repertoire and often show self-reactivity [1]. The close proximity of these cells and intestinal antigens 
is, however, turned safe via multiple barriers and regulatory ways. As for nondangerous antigens that cross the intestinal barrier, there are numerous mechanisms that avoid local or systemic immunization. For example, TCR $\gamma \delta^{+}$intestinal intraepithelial lymphocytes secrete keratinocyte growth factor at the sites of mucosal injury, which helps to restore the epithelial layer. In turn, the intact epithelial cells are involved in the priming of $\mathrm{CD} 8^{+} \mathrm{TCR} \gamma \delta^{+}$regulatory $\mathrm{T}$ cells that secrete relevant amounts of IL-10 and mediate significant anti-inflammatory effect [1]. The fine spatial organization of the intestinal network is also noticeable under physiological circumstances. Obata et al. have discovered intratissue colonization of the intestinal mucosa by commensal bacteria, which does not show accidentality, but rather a strict spacial structure under physiological circumstances [10]. In a mouse model, the surface of Peyer's patches (PP) is mainly (98\%) colonized by segmented filamentous bacteria while the bacterial composition of PP interior consists of Alcaligenes spp. (72\%), Ochrobactrum spp. (10\%), Serratia spp. (6\%), Burkholderia spp. (4\%), and a minor percentage of others. Undiscriminated species were present throughout the surface layer of the lamina propria. The bacterial composition of dendritic cells (DCs) in Peyer's patches and mesenteric lymph nodes was also different with Alcaligenes spp. dominating in the former and Pseudomonas spp. dominating in the latter case in mice. The ability of Alcaligenes to colonize human and nonhuman primate (monkey) Peyer's patches was also shown [10]. Besides intestinal microbes, members of the mucosal immune apparatus as well have a strictly determined niche to live. A distinct pattern of intestinal intraepithelial lymphocyte (iIEL) populations in different regions of the gut was shown to be present both in human and rodents [11-13]. The activation and homing properties of peritoneal B-1 lymphocytes are also strictly regulated [1]. Intestinal dendritic cells, which are able to hold live commensal bacteria for several days, are as well retained to a well-determined niche via mesenteric lymph nodes, that function as a filter for these cells as shown by a mouse model [14]. This way, the mucosal immune responses are kept partially separated from the systemic compartment, allowing local IgA production but avoiding inadequate immunization with enteral bacteria and potential consequent enterocolitis or autoimmune complications.

Commensal bacteria as well form an active part of the intestinal community. Besides the production of vitamin $\mathrm{K}$ [15], these microbes help to digest complex carbohydrates, thus allowing access to short-chain fatty acids (SCFAs), that serve as nutrients for intestinal epithelial cells beyond regulating their differentiation and growth $[9,16]$. Microbes also induce the production of intestinal mucus $[17,18]$. In the colon, mucus consists of two layers, of which the inner one is densely packed, adhering to the epithelium and physically preventing penetration of bacteria, as demonstrated on a mouse model [19]. Beyond its barrier function, intestinal mucus is believed to shape the composition of the microbial flora via offering special adhesion epitopes [9]. Gut bacteria also play a crutial role in the regulation of mucosal immune responses. Molecules recognizing the intestinal microflora are diverse, including numerous pathways like Toll-like receptors (TLRs), formylated peptide receptors (FPRs), nucleotide binding oligomerization-like receptors (NODs), IL- $1 \beta$-converting enzyme protease activator factor (IPAF), and C-type lectins with corresponding signal transduction routes. Inflammatory and proapoptotic responses go hand in hand, where NF- $\kappa$ B plays a key role. Many commensal species limit NF- $\kappa \mathrm{B}$-dependent signalling and induce the production of TGF- $\beta$, mediating anti-inflammatory and antiapoptotic effects [9]. Certain members of the gut microflora were also reported to shape the $\mathrm{T}_{\text {reg }} / \mathrm{T}_{\mathrm{H} 17}$ balance in the mucosa and induce immunity against intestinal pathogens via a $\mathrm{T}_{\mathrm{H} 17}$-dependent response in mice. $\mathrm{T}_{\mathrm{H} 17}$ cells represent a special population of $\mathrm{CD} 4^{+} \mathrm{T}$ lymphocytes, which produce IL-17, IL-17F, as well as IL-22, and play a role in inflammatory responses against bacterial and fungal pathogens. Molecular details of the induction of $\mathrm{T}_{\mathrm{H} 17}$ cells are recently being discovered [20-22].

Considering the fine organization of the intestinal mucosal tissues, the huge amount of potentially dangerous microbes and the vulnerable balance between inflammation and tolerance as well as symbiosis and bacterial invasivity, the role of mucosal immunity in the pathomechanism of critical illness is most comprehensible. The gut as a motor of systemic inflammation (either of an infective origin or not) and multiple organ failure was first described in the 80s, when an impaired intestinal barrier function along with bacterial translocation in an already immunocompromised host was believed to play a pivotal role $[23,24]$. Since then, the growing number of experimental data has refined our knowledge; however, the majority of these come from animal models, eminently rodents, which needs to be taken into account. This review provides a short overview of the field.

\section{Changes in the Intestinal Environment in Critical Illness}

\subsection{Physiological Regulation of the Intestinal Environment.} Under physiological circumstances, the composition of the intestinal microbial flora is strictly controlled by mucosal tissues as well as the microbes themselves, which is crutial for the maintenance of a healthy symbiosis. Molecular mechanisms involved in this process are highly diverse and go far beyond the secretion of IgA antibodies. Angiogenin 4, an antibacterial peptide secreted by Paneth cells, is induced by commensal organisms and it is believed to help to maintain the Gram-negative predominance in the gut via its antiGram-positive spectrum [24, 25]. Similarly, RegIII $\gamma$, another antibacterial agent, is induced by the microbes themselves [26]. Defensins possessing both direct antibacterial and immunomodulatory potential, along with broad-spectrum antimicrobial product cryptdins also contribute to shaping the composition of the intestinal microflora. Intermicrobial interactions, special adhesion epitopes present on mucin proteins as well as the presence of fucosylated glycans (serving as nutrient for some microbes) were also shown to have an effect on the gut microbiome $[9,27]$. Another mechanism involves a special population of $\mathrm{T}$ lymphocytes that modulate the NOD2-dependent activation of epithelial 
cells in response to bacterial peptidoglycans, as demonstrated by a mouse model. These $\mathrm{CD}^{+} \mathrm{CD} 11 \mathrm{c}^{+} \mathrm{T}$ cells express PGLYRP-2 that destroys the NOD2-recognising epitope of peptidoglycans, which is preserved by enteral lyzozime. PGLYRP-2 positive cells belong to a mixed TCR $\alpha \beta^{+} / \mathrm{TCR} \gamma \delta^{+}$ population, express B220 and CD69 activation markers and reduce NOD2-mediated epithelial cell activation via PGLYRP-2. This effect was reported to affect the composition of the commensal flora [28]. The maintenance of the physiological intestinal environment is also dependent on a heterogeneous population of regulatory $\mathrm{T}$ lymphocytes, including $\mathrm{CD}^{+}, \mathrm{CD}^{+}$, as well as $\mathrm{TCR} \gamma \delta^{+}$cells, that are engaged with the ability to suppress immunity against nondangerous intestinal antigens. Intestinal epithelial cells along with dendritic cells of the lamina propria and mesenteric lymph nodes are involved in the priming of regulatory lymphocytes [1]. A healthy microbiome, in turn, induces a tolerogenic, antiapoptotic milieu, regulates its own composition, provides access to otherwise inaccessible nutrient factors (e.g., short-chain fatty acids), and suppresses pathogenic species.

\subsection{Alteration of the Intestinal Microenvironment in Crit-} ical Illness. In life-threatening states, there are numerous factors contributing to the pathological alteration of the intestinal microbial community [29]. Systemic antibiotics, splanchnic ischemia-reperfusion, mucosal acidosis, impaired production of mucins, and appearance of bacterial derivatives in the blood along with the lack of local nutrients (either as a consequence of total parenteral nutrition or highly processed enteral nutrients resulting in distal bowel nutrient deficiency) may occur and contribute to enhanced apoptosis, histological disorganization of the mucosa, and change of the intestinal microbial composition. The abovementioned regulatory ways which shape the gut microbiome are impaired in injured mucosal tissues, which is augmented by the pathological shift in the microflora itself.

Many widely used broad-spectrum antibiotics were reported to have a profound effect on the composition of the intestinal microbial community even in healthy human volunteers. Intravenously (i.v.) administered cefoperazone dramatically reduced numbers of both aerobic and anaerobic bacteria; however, it induced a massive overgrowth of yeasts. Piperacillin (i.v.) had similar, but less profound effects [30]. Parenterally administered ceftriaxone may also induce Candida overgrowth in humans [31], along with intravenous ciprofloxacin in a part of volunteers [32]. Increased presence of yeasts in the intestinal content may be particularly dangerous in critical illness, since Candida albicans was reported to facilitate the translocation of Escherichia coli through the epithelial barrier in vitro [33].

A profound change in the intestinal milieu was revealed in patients with severe systemic inflammatory response syndrome (SIRS). The reduced number of intestinal obligate anaerobes in SIRS compared to normal (among these strains Bacteroidaceae, Bifidobacterium, and Veillonella sp.) along with a decreased occurrence of Lactobacillus was reported, while Staphylococcus and Pseudomonas numbers increased significantly. The total amount of organic acids (particularly butyric acid, propionic acid, and acetic acid) was reduced while the $\mathrm{pH}$ was elevated in the intestinal content of patients with SIRS [34]. Furthermore, an altered gut flora (a decrease in total obligate anaerobes and an increase in pathogenic bacteria) might be a prognostic marker in these patients [35]. Critical illness-associated changes in the intestinal flora may occur surprisingly rapidly, as shown by a rat model of pancreatitis, where anaerobic bacteria and Lactobacilli numbers in the colon and the distal small intestine decreased from 6 to 12 hours [36]. Special nutrition protocols also have a marked effect on the composition of the intestinal environment. Fiber-free total enteral nutrition resulted in a decrease of anaerobic and an increase of aerobic bacteria in the fecal flora of human subjects. Total parenteral nutrition was shown to reduce the number of both aerobic and anaerobic bacteria, and induced a decrease of short-chain fatty acids compared to the fiber-free enteral nutrition group [37].

2.3. Regulation of Bacterial Virulence. Changes of the gut microbial flora and the intestinal microenvironment in citically ill patients are particularly relevant considering the mechanism of quorum sensing (QS) $[29,38]$. QS is a system for the regulation of virulence genes in bacteria that comes into play beyond a critical bacterial density. QS molecules provide opportunity for cell-to-cell communication in bacterial communities to coordinate and synchronize their behaviour, when bacteria sense a threat of elimination under circumstances of high density and the lack of nutrients. In these cases, a synchronized program for overwhelming the host may be profitable for bacteria, even considering the presence of host immunity and antibiotics. Indeed, mediators released from ischemic, hypoxic, or injured tissues (such as stressed intestinal epithelia) are potent activators of the QS system in Pseudomonas aeruginosa [29]. One of the mediators released by this bacterium this way (2heptyl-4-hydroxyquinoline-N-oxide) directly suppresses the growth of Lactobacilli sp., further enhancing the chance to invade the host [39]. A mouse model revealed that QS activation results in the production of PA-I lectin in P. aeruginosa, which increases tight junctional permeability, giving free way to the systemic dissemination of ribosylating toxin exotoxin A, that induces a lethal septic response [29]. QS circuits were also found to activate in response to INF $\gamma$ in this bacterium, resulting in enhanced virulence, adhesion to the epithelium and disruption of the epithelial barrier $[29,38]$. These findings may explain much of the observed discrepancies regarding the theory of "gut as the motor of sepsis." The original theory was based on the conception that bacteria translocating to the circulation through the injured intestinal barrier in critical illness facilitate systemic inflammatory responses and contribute to the development of multiple organ dysfunction syndrome (MODS). This model was supported by the fact that germ-free animals improved survival after hemorrhagic shock/intestinal ischemia-reperfusion compared to controls $[40,41]$. However, the number of translocated bacteria was not enough to induce sepsis when injected into healthy animals, and similarly, the clinically observed amount of lipopolysaccharide (LPS) was not sufficient to induce 
a systemic inflammatory response similar to septic states. The presence of quorum sensing, however, may provide an explanation how the activation of virulence genes may endow these bacteria to induce significant changes in the host homeostasis [29, 42].

\section{Gut-Microbe Interactions and Intestinal Barrier Function in Critical Illness}

3.1. Bacterial Contribution to the Intestinal Barrier. The intestinal barrier consists of multiple mechanisms including mucus production, epithelial layer junctional complexes, as well as the mucosal immune apparatus including IgA antibodies along with cellular components. Under physiological circumstances, commensal microbes actively contribute to the maintenance of the gut barrier function through multiple ways. They competitively antagonize epithelial adherence and suppress growth of pathogenic species, induce the production of IgA antibodies and mucus, digest macromolecules to decrease antigenic load, and provide access to SCFAs $[9,43]$. Short-chain fatty acids were reported to serve as nutrients for epithelial cells, regulate their growth and differentiation, decrease the in vitro permeability of intestinal tight junctions, and induce production of cytoprotective heat shock protein 25 (HSP25) as well as mucin (MUC2) $[9,16,44-47]$. The induction of protective heat shock proteins (HSPs) was also reported directly by Bacillus subtilis derivatives [29]. Another effect of SCFAs is the induction of ornithine-decarboxylase, the enzyme catalyzing the ratelimiting step of polyamine synthesis. These mediators have been demonstrated to play an important role in normal cell growth and repair of injuries in the mucosa [48].

Under circumstances of critical illness, which alters intestinal environment and microflora, disadvantageous microbial contribution to the barrier functions gain particular importance. Numerous bacteria or bacterial products including enteropathogenic Escherichia coli (EPEC), Clostridium difficile toxins, Vibrio cholerae as well as Pseudomonas aeruginosa PA-I lectin were shown to increase intestinal permeability via modulation of junctional complexes in epithelial cells $[9,29]$. Their exact way of action involve multiple molecular mechanisms; however, all result in the impairment of barrier function. Inversely, Bifidobacteria along with Bacillus subtilis were shown to act advantageously on the intestinal barrier $[29,49,50]$.

Beyond local effects, microbial presence may also affect the gut barrier from remote tissues like lungs (however, pneumonia-related hypoxia and septic hemodynamic disturbances may contribute to these effects). Intratracheal inoculation of Pseudomonas aeruginosa was shown to induce intestinal epithelial cell cycle arrest in a mouse model [51], while other experiments revealed IEC apoptosis in experimental Pseudomonas pneumonia. Bcl-2 overexpressing mice improved survival in this model, but the question of bacterial translocation was not considered to be the predominant mechanism responsible for the survival benefit [52]. Interestingly, Bcl-2 overexpression did not improve survival in LPS-induced acute lung injury in mice [53]. As for Gram-positive pathogens, intratracheal inoculation of Streptococcus pneumoniae induced MODS and intestinal leak in mice, despite the fact that relatively low number of bacteria gained access to the circulation. This effect appeared to be a transient change, suggesting that intestinal epithelial apoptosis or necrosis did not occur [54]. Neither Grampositive ( $S$. pneumoniae) nor Gram-negative (P. aeruginosa) pneumonia induced apoptosis in airway epithelial cells [55].

3.2. Cellular and Molecular Mechanisms Involved in the Alteration of Physical and Immunological Barrier Function. Intestinal epithelial cells, intraepithelial lymphocytes, Peyer's patches, mesenteric lymph nodes and the lamina propria immune apparatus are all involved in physiological immune barrier functions in the gut. Intestinal ECs are polarized cells, possess the ability to present antigens as nonprofessional antigen presenting cells (APCs), and were shown to express classical MHC I, MHC II, as well as nonclassical MHC I. The secretion of MHC-containing, antigen-loaded microparticles was also reported [56-58]. The latter mechanism may provide information to bystander cells on the antigenic composition of the luminal content. Intestinal intraepithelial lymphocytes contribute to host protection both as regulators of the inflammatory response [59] and via the induction of mucosal repair: TCR $\gamma \delta^{+}$iIELs were reported to secrete keratinocyte growth factor $(\mathrm{KGF})$, required for restoring intestinal epithelia [60]. However, critical illness is characterized by major changes in the function of the mucosal immune barrier. Polymicrobial sepsis as well as intestinal ischemia-reperfusion were reported to induce a dramatic loss of lymphocytes in the intraepithelial and lamina propria compartments as well as in Peyer's patches. Although critical illness seems to affect effector sites more profoundly than inductive sites, it is important to note that the number of lymphocytes in the lamina propria recovers more quickly than in Peyer's patches. Increased apoptosis among ilELs and lamina propria B cells was considered to be Fas-FasL but not endotoxin mediated. [24, 61-63]. A mouse model has shown that TCR $\gamma \delta^{+}$iIELs seem to play an important role in the pathomechanism of polymicrobial sepsis, since their percentage becomes higher within the intraepithelial compartment of the small intestine in sepsis, and $\gamma \delta^{-/-}$mice show an increased early mortality following cecal ligation and puncture [59].

Beyond cellular components, physical and humoral barrier functions were also reported to be impaired in critical illness. The production of intestinal mucus was decreased in a rat model of trauma/hemorrhagic shock, where females had better survival rates associated with a more efficient preservation of the gut mucus layer and the barrier function, suggesting an important role of sexual differences [64-66]. The expression of intestinal trefoil factor 3 (TFF3), which stabilizes the mucus layer and contributes to the repair of mucosal injuries, was reported to decrease in a rat model of polymicrobial sepsis, along with defensin 5 (RD-5), a wide-spectrum antimicrobial product of Paneth cells [67]. The expression of ornithine decarboxylase, a key enzyme of polyamine synthesis, was, however, increased in a rat model of severe burn injury, and this process played a role in mucosal repair [68]. IgA-mediated humoral response is 
defective in several rodent models of critical illness including endotoxemia and burn injury, and this state associates with an impaired function of the intestinal barrier. Human subjects with intra-abdominal sepsis also had a reduced IgA-mediated response [69-71], which might be associated with enhanced apoptosis or potentially the sepsis-induced impairment of the mucosal production of IL-5 (known from a murine model), a cytokine that normally promotes IgA class switch [72]. However, others demonstrated an elevated number of IgA secreting lamina propria B cells in septic mice [63]. Besides its well-known adverse effects [73], hyperoxia was shown to enhance barrier function in synergism with IgA in vitro [74, 75]. Beyond immunoglobulin-mediated protection, the epithelium itself also serves as a barrier, and the cytokine milieu has a clear impact on the permeability of this layer: INF $\gamma, \mathrm{TNF} \alpha$, high-mobility group B1 (HMGB1), IL-2, IL-4, IL-13, and a RAGE-dependent signal increases permeability while IL-10 and TGF $\beta$ act oppositely [7681]. INF $\gamma$ may also mediate transcytosis of Escherichia coli through epithelial cells in vitro via lipid raft structures [82], which is an additional mechanism independent of tight junctions. The excess production of $\mathrm{NO}$ was found to be required for the development of enhanced intestinal permeability after hindlimb ischemia-reperfusion or the administration of LPS. In the latter case, the changes were associated with the altered expression and localization of key tight junction proteins $[83,84]$. Inversely, IGF-1 was reported to be protective via the attenuation of sepsisinduced intestinal epithelial apoptosis in mice. Higher IGF1 levels were associated with reduced bacterial translocation both in human subjects and the mouse model [85].

\subsection{Impact of Some Therapeutic Efforts on the Intestinal} Barrier Function. Besides microbe-host interactions, therapeutic efforts also influence the intestinal barrier in critical illness, although detailed experimental data are poorly available. The impact of antibiotics on the intestinal community was mentioned above. Considering animal models, steroid drugs seem to impair mucosal barrier function via multiple ways. Intraperitoneal administration of dexamethasone was found to reduce IgA production, enhance bacterial adherence to the mucosa, and facilitate translocation of bacteria from the intestinal lumen to mesenteric lymph nodes in nonseptic, intact rats. In mice with severe burn injury, prednisone facilitated the translocation of Escherichia coli to the intestinal wall as well as mesenteric lymph nodes $[86,87]$. In vivo exposure to lidocaine was also associated with bacterial translocation, along with a decreased proliferation and $\mathrm{T}_{H 2}$ cytokine production of T-cells in Peyer's patches in mice [88]. Inversely, propofol was shown to mediate a protective effect on the gut via the reduction of intestinal permeability, mucosal TNF $\alpha$ and IL- 6 production, NF- $\kappa$ B activity, as well as plasma endotoxin levels in rats with traumatic brain injury [89]. Both selective COX-2 inhibition and the administration of indomethacin (a nonselective COX inhibitor) induced enhanced apoptosis in mesenteric lymph nodes, and attenuated the increase of macrophages in the mucosa and MLNs in septic rats. However, selective COX-2 inhibition was reported to decrease liver injury in a rat model of polymicrobial sepsis $[90,91]$. Vasopressor agents like norepinephrine (NE) are widely used in the management of septic shock-related hypotension. Norepinephrine dose was in a direct correlation with lactic acidosis of the rectal mucosa in patients with septic shock; however, it remains obscure if the vasopressor agent istelf or a more severe shock requiring higher NE doses is responsible for this observation [92].

\section{Interactions between the Intestinal and Systemic Compartments in Critical Illness}

The exact way how events in the altered intestinal microenvironment disturb host homeostasis in critical illness is yet unknown in details; however, recent investigation has revealed many relevant pathways. The regulation system of bacterial virulence, which provides a coordinated program for the impairment of the mucosal barrier and systemic spread of bacteria/bacterial products leading to a fatal septic response in the host, was described earlier in Section 2. Like extraintestinal tissues, gastric and intestinal mucosa is engaged with the ability to respond to inflammatory signals via production of different mediators. Endotoxemia in a mouse model resulted in the production of IL- 6 in small intestine and colonic mucosa, which was mainly related to enterocytes along with a few cells in the lamina propria. IL-1 $\beta$ induced a similar effect in the small intestine [93]. The widespread apoptosis observed in the intestinal mucosa in critical illness might however mediate immunparalysis via the well-known ability of apoptotic cells to induce immunosuppression [94], in case they gain access to the systemic compartment.

The pathogenic role of certain gut-derived products in the development of multiple organ dysfunction syndrome was demonstrated years ago [23]. However, the level of C3a, IL-6, and tumor necrosis factor was nearly identical in simultaneously collected portal and systemic blood samples in patients with major torso trauma [95]. Similarly, portal and systemic levels of IL- $1 \beta$, TNF $\alpha$, and IL- 6 did not differ significantly in a rat model of polymicrobial sepsis [96]. The gut-origin lymph was, however, demonstrated to serve as a primary route of nonbacterial intestinal products associated with tissue injury in a trauma/hemorrhagic shock model. Lymph derived from the stressed intestine, which gains access to the systemic circulation via the thoracic duct, may induce multiple organ dysfunction syndrome (MODS) and acute respiratory distress syndrome (ARDS), which is otherwise called the "gut-lymph hypothesis." The exact way how gutorigin lymph disturbs homeostasis is yet obscure; however, pathways involving TLR4 signalling as well as NO excess seem to be involved. [97]. Besides gut-origin lymph, gutorigin norepinephrine also seems to be involved in sepsis pathophysiology. A rat model has shown that during early sepsis, gut itself may be a relevant source of norepinephrine, which enters the hepatic circulation via the portal vein, and induces dysfunction of hepatocytes possibly mediated via the upregulation of inflammatory cytokine production [98]. 


\section{The Impact of Nutrition Protocols on Mucosal Immunity in Critical Illness}

5.1. The Intestinal Mucosa in Total Parenteral Nutrition. Total parenteral nutrition (TPN), which we mean here as parenteral nutrition with the lack of enteral nutrition, is occasionally inevitable in the management of critically ill patients. However, associated side effects on mucosal immunity and the intestinal microenvironment are worth an exceptional attention, considering the role of the gut in the pathomechanism of various life-threatening states. Alteration in the composition of the intestinal microflora associated with TPN was described earlier in Section 2. Murine experiments have shown that TPN-associated adverse effects included enhanced epithelial cell apoptosis, increased degree of bacterial translocation from the intestinal lumen, histologically decreased height of the villus-crypt complex, as well as alterations in the intestinal intraepithelial lymphocyte population. The numbers of $\mathrm{CD} 4^{+} \mathrm{CD} 8^{-}, \mathrm{CD} 4^{+} \mathrm{CD} 8^{+}$, $\mathrm{CD} 8 \alpha \beta^{+}$thymus-dependent along with $\mathrm{CD} 8^{+} \mathrm{CD} 44^{+}$mature iIELs were found to decrease in response to total parenteral nutrition. The cytokine profile of iIELs also changed as the levels of IL-2 and IL-10 mRNAs decreased, inverse to the increased expression of IL-6, INF $\gamma$, IL-4, TGF $\beta 1$, as well as TNF $\alpha$ mRNAs. These changes were demonstrated to associate rather with the lack of enteral nutrition but not the presence of parenteral nutrition [99, 100]. Both the lack of iIEL-derived IL-10 and the overproduction of INF $\gamma$ contributed to the decreased gut barrier function in mice $[101,102]$. TPN as well as fiber-free enteral nutrition was demonstrated to decrease jejunal IgA and insoluble mucin levels as well, along with the increase of intestinal permeability and bacterial translocation in rats [103]. The fall of lymphocyte numbers in Peyer's patches, intraepithelial space, and lamina propria in response to total parenteral nutrition was also reported in a mouse model [104]. Antigen recognition pattern changes as well, as another murine model revealed upregulated expression of TLR4, TLR5, TLR7, and TLR9 mRNAs in response to total parenteral nutrition, particularly in the distal part of the small intestine [105], which might be consequent to an altered bacterial environment. Studies on the molecular pathways involved in TPN-associated mucosal disturbances have demonstrated the important role of IL-7, a critical factor for the maintenance of several lymphoid tissues. The production of this cytokine by intestinal epithelial cells was found to be impaired when mice were on TPN, which associated with reduced number and altered phenotype of iIELs. External supplementation of IL-7 as well as intestinal overexpression of IL-7 restored much of these changes $[106,107]$.

5.2. Immunonutrition and Probiotics in Critical Illness. Supplementation of nutrition protocols with certain immunomodulatory-nutrient agents may have a profound effect on mucosal immunity as demonstrated by several animal models, and the quest for possibilities of human clinical application has been in the focus of research. Glutamine supplementation of total parenteral nutrition in mice was shown to attenuate TPN-induced changes in the intestinal mucosa. Total parenteral nutrition associated with an impaired barrier function, decreased number of intraepithelial lymphocytes, and increased INF $\gamma$ but decreased IL10 expression in iIELs. Glutamine-supplementation of TPN resulted in a significant preservation of the barrier function, in which the influence on ilEL cytokine profile (prevention in the overproduction of INF $\gamma$ and decline in IL-10) may play a role. The way how glutamine affected the cytokine production of iIEL cells was independent on the IL-7 pathway [108]. Glutamine supplementation in a TPN model was also demonstrated to reverse the TPN-induced fall in the intestinal and airway IgA production [109], and restored lymphocyte numbers in the intraepithelial compartment, lamina propria and Peyer's patches in mice. Glycyl-Lglutamine supplementation had similar effect as glutamine on the TPN-associated atrophy of gut-associated lymphoid tissue [104]. Glutamine was also demonstrated to attenuate the TPN-induced decline of IL-10 and IL-4 mRNA levels in lipopolysaccharide- (LPS-) stimulated lamina propria cells in mice, and the expression of these mRNAs correlated with the amount of intestinal IgA [110]. Glutamine also helped to maintain T-lymphocyte populations in Peyer's patches and the production of IgA in a rat model of polymicrobial sepsis [111]. An "immunoenhancing" enteral diet supplemented with L-arginine, $\omega$-3 fatty acids, and RNA fragments in septic but not control rats was shown to increase the production of IL-5 and IL-6, cytokines that promote IgA immunoglobulin class switch [72]. IL-5 was also demonstrated to be required for an optimal T-cell-dependent activation of murine B1 lymphocytes. B-1 cells produce natural antibodies that contribute to the first-line protection against infectious agents [112-114]. Supplementation of TPN with shortchain fatty acids was also found to have a protective effect on the intestinal mucosa via multiple mechanisms. After massive short bowel resection in rats, SCFA supplementation of TPN upregulated the mucosal expression of ornithine decarboxylase as well as proglucagon mRNA levels, that might be the way by which SCFAs facilitate intestinal adaptation [48]. Indeed, both polyamine synthesis catalyzed by ODC and abundance of proglucagon derivatives were shown to associate with an advantageous effect on the intestinal mucosa $[68,115]$. SCFA supplementation was also found to enhance ileal proglucagon mRNA expression in intact rats subjected to TPN [116]. Bulk-forming fibers as well proved to be worthy attention, since per os fiber supplementation of fiber-free enteral nutrition or TPN resulted in a decreased intestinal permeability along with a lower degree of bacterial translocation in rats [103].

The management of intestinal dysbacteriosis associated with critical illness includes two plausible solutions: selective digestive decontamination (SDD) or the administration of probiotics. Conclusions from the literature demonstrate that the prophylactic use of SDD may reduce infections, eminently pneumonia, as well as mortality in a mixed population of ICU patients; however, no studies focused specifically on severe sepsis and septic shock [117]. The use of probiotics proved to have a protective effect on the intestinal mucosa in several animal models, eminently rodents. In rats subjected to short bowel resection, oral 


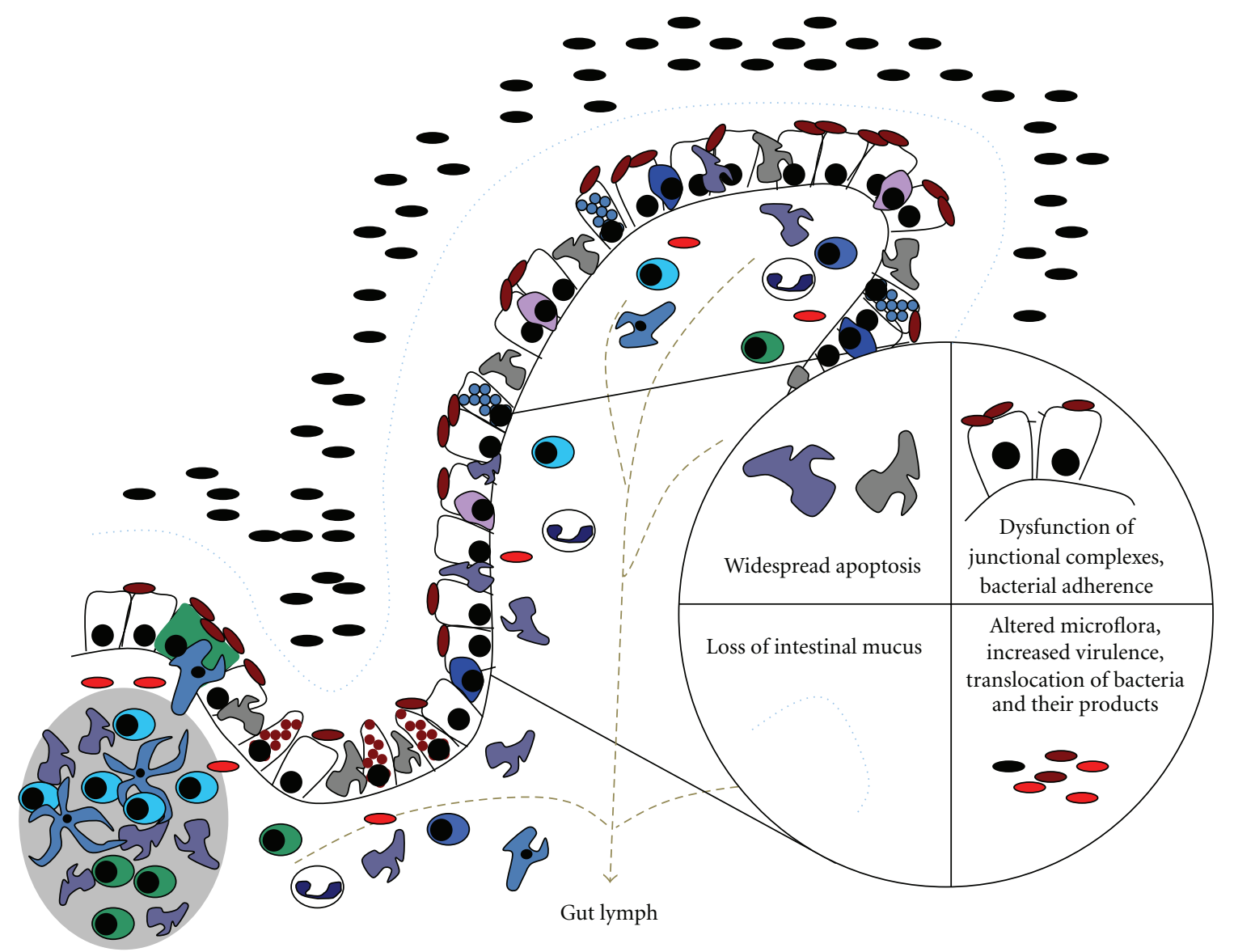

Peyer's patch
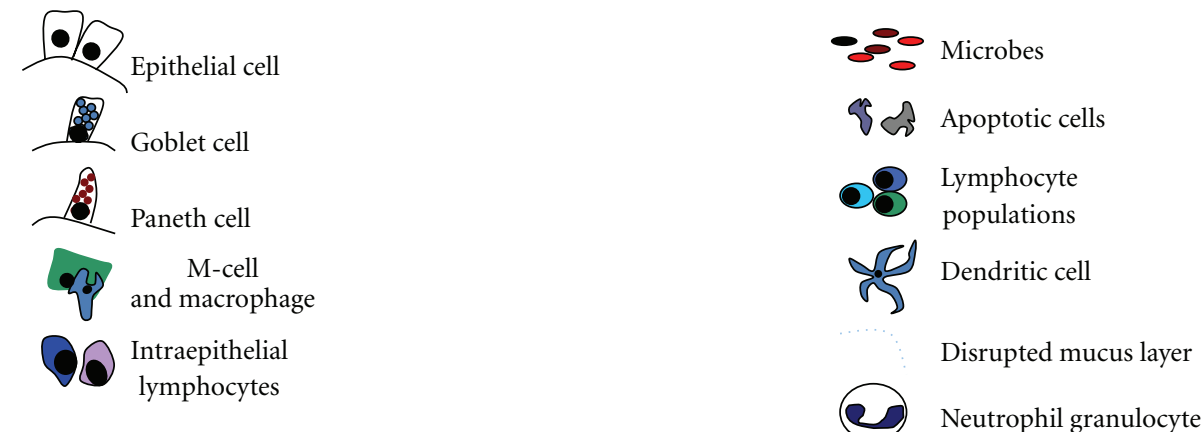

FIGURE 1: Major changes in the gut mucosa under the circumstances of critical illness. Injured mucosal tissues with widespread apoptosis, histological disorganization, and a disrupted intestinal barrier face an altered microbial flora with pathological composition and increased virulence. Damageous products from the stressed intestine gain access to the gut lymph.

treatment with probiotics reduced bacterial translocation from the intestinal lumen and decreased intestinal epithelial cell apoptosis [118]. Another murine model demonstrated that orally administered lyzozyme-modified Lactobacillus sp. improved survival of polymicrobial sepsis, which was associated with an increase in the bacterial clearance in the liver. These lyzozyme-modified probiotic components (LzMPC) were shown to cross the intestinal barrier and get engulfed by liver macrophages. LzMPC stimulated the in vitro production of cathelicidin-related antimicrobial peptide (CRAMP) in these cells and potentiated their bactericidal activity. Polymicrobial sepsis was also shown to decrease the expression of CRAMP in the liver, which was restored by the administration of LzMPC [119]. However, in contrast to these animal models, data on the human clinical application of both immunonutrition and probiotics in critically ill patients remains controversial, furthermore, cases of Lactobacillus sepsis in connection with probiotic 


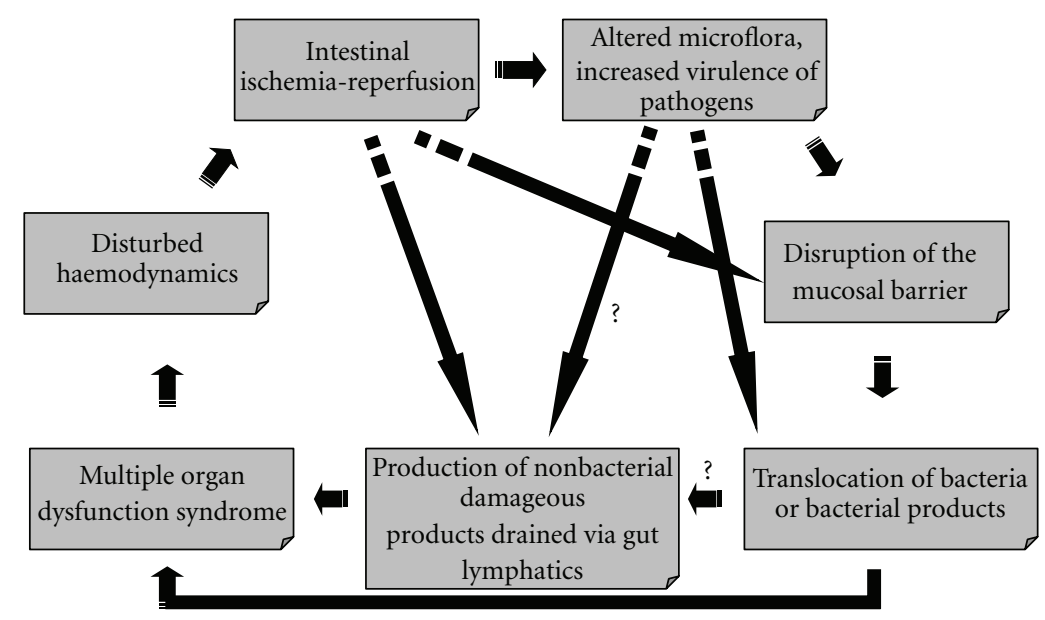

FIGURE 2: A schematic hypothetical model for the interactions between intestinal microbes, the splanchnic and the systemic compartments in the pathomechanism of multiple organ dysfunction syndrome.

therapy were also reported. It is likely that the administration of the right combination of immunoenhancing supplementaries or probiotics in the right patient population at the right time might potentially be beneficial; however, further research is required for a better understanding of the biology of MODS [120-123].

\section{Concluding Remarks}

The intestinal microbiome and mucosal tissues are intertwined by multiple interactions both in health and disease. Under physiological conditions, the splanchnic community-procaryotic and eucaryotic members hand in hand-serves the host via several ways, only one of which is the supply with nutrients. In the critically ill host, however, this advantageous balance is seriously injured, as benign commensals sensing danger rapidly switch to feared pathogens and initiate a coordinated program to invade the succumbed tissues. This way, the intestinal microflora may be regarded as a "shock tissue," and the microbiome-gut complex as a "shock organ" in a wider sense. Pathogens, as well as bacterial and nonbacterial damageous agents disseminate systemically and contribute to the development of multiple organ dysfunction syndrome. A brief summary of these events is presented on Figures 1 and 2. Today, 25 years after the first report on the hypothesis of "gut as the motor of multiple organ failure," the pivotal role of the injured intestine in the development of critical illness is still in the focus of research. Hopefully, a better understanding of the biology of MODS/MOF will lead to the development of more sophisticated therapeutic tools and improved survival of patients.

\section{Acknowledgments}

The financial support of the Hungarian Ministry of Culture and Education under Grant no. TÁMOP-4.2.2-08/1/20080018 as well as a Sanofi-Aventis scholarship is gratefully acknowledged. K. Madách and K. Kristóf contributed equally to this work.

\section{References}

[1] K. Kristóf, A. Erdei, and Z. Bajtay, "Set a thief to catch a thief: self-reactive innate lymphocytes and self tolerance," Autoimmunity Reviews, vol. 7, no. 4, pp. 278-283, 2008.

[2] K. Kristóf, K. Madách, I. Czaller, Z. Bajtay, and A. Erdei, "Mathematical analysis of clinical data reveals a homunculus of bacterial mimotopes protecting from autoimmunity via oral tolerance in human," Molecular Immunology, vol. 46, no. 8-9, pp. 1673-1678, 2009.

[3] J. Ochoa-Repáraz, D. W. Mielcarz, L. E. Ditrio et al., "Role of gut commensal microflora in the development of experimental autoimmune encephalomyelitis," Journal of Immunology, vol. 183, no. 10, pp. 6041-6050, 2009.

[4] O. Vaarala, "Leaking gut in type 1 diabetes," Current Opinion in Gastroenterology, vol. 24, no. 6, pp. 701-706, 2008.

[5] J. Penders, C. Thijs, P. A. van den Brandt et al., "Gut microbiota composition and development of atopic manifestations in infancy: the KOALA birth cohort study," Gut, vol. 56, no. 5, pp. 661-667, 2007.

[6] J. Penders, E. E. Stobberingh, P. A. V. D. Brandt, and C. Thijs, "The role of the intestinal microbiota in the development of atopic disorders," Allergy, vol. 62, no. 11, pp. 1223-1236, 2007.

[7] E. Isolauri, "Intestinal involvement in atopic disease," Journal of the Royal Society of Medicine, vol. 90, supplement 30, pp. 15-20, 1997.

[8] M. Vijay-Kumar, J. D. Aitken, F. A. Carvalho et al., "Metabolie syndrome and altered gut microbiota in mice lacking toll-like receptor 5," Science, vol. 328, no. 5975, pp. 228-231, 2010.

[9] J. Neu, R. Sharma, and C. Young, "Molecular modulation of intestinal epithelial barrier: contribution of microbiota," Journal of Biomedicine and Biotechnology, vol. 2010, Article ID 305879, 2010.

[10] T. Obata, Y. Goto, J. Kunisaw et al., "Indigenous opportunistic bacteria inhabit mammalian gut-associated lymphoid tissues and share a mucosal antibody-mediated symbiosis," 
Proceedings of the National Academy of Sciences of the United States of America, vol. 107, no. 16, pp. 7419-7424, 2010.

[11] C. Lundqvist, V. Baranov, S. Hammarstrom, L. Athlin, and M. L. Hammarstrom, "Intra-epithelial lymphocytes. Evidence for regional specialization and extrathymic T cell maturation in the human gut epithelium," International Immunology, vol. 7, no. 9, pp. 1473-1487, 1995.

[12] H. Suzuki, "Differences in intraepithelial lymphocytes in the proximal, middle, distal parts of small intestine, cecum, and colon of mice," Immunological Investigations, vol. 38, no. 8, pp. 780-796, 2009.

[13] H. Suzuki, K. I. Jeong, T. Okutani, and K. Doi, "Regional variations in the distribution of small intestinal intraepithelial lymphocytes in three inbred strains of mice," Journal of Veterinary Medical Science, vol. 62, no. 8, pp. 881-887, 2000.

[14] A. J. Macpherson and T. Uhr, "Induction of protective IgA by intestinal dendritic cells carrying commensal bacteria," Science, vol. 303, no. 5664, pp. 1662-1665, 2004.

[15] J. M. Conly and K. Stein, "The production of menaquinones (vitamin K2) by intestinal bacteria and their role in maintaining coagulation homeostasis," Progress in Food and Nutrition Science, vol. 16, no. 4, pp. 307-343, 1992.

[16] L. H. Augenlicht, G. M. Anthony, T. L. Church et al., "Shortchain fatty acid metabolism, apoptosis, and Apc-initiated tumorigenesis in the mouse gastrointestinal mucosa," Cancer Research, vol. 59, no. 23, pp. 6005-6009, 1999.

[17] D. R. Mack, S. Ahrne, L. Hyde, S. Wei, and M. A. Hollingsworth, "Extracellular MUC3 mucin secretion follows adherence of Lactobacillus strains to intestinal epithelial cells in vitro," Gut, vol. 52, no. 6, pp. 827-833, 2003.

[18] C. L. Ohland and W. K. MacNaughton, "Probiotic bacteria and intestinal epithelial barrier function," American Journal of Physiology-Gastrointestinal and Liver Physiology, vol. 298, no. 6, pp. G807-G819, 2010.

[19] M. E. V. Johansson, M. Phillipson, J. Petersson, A. Velcich, L. Holm, and G. C. Hansson, "The inner of the two Muc2 mucin-dependent mucus layers in colon is devoid of bacteria," Proceedings of the National Academy of Sciences of the United States of America, vol. 105, no. 39, pp. 15064-15069, 2008.

[20] I. I. Ivanov, K. Atarashi, N. Manel et al., "Induction of intestinal Th17 cells by segmented filamentous bacteria," Cell, vol. 139, no. 3, pp. 485-498, 2009.

[21] K. Atarashi, T. Tanoue, and K. Honda, "Induction of lamina propria Th17 cells by intestinal commensal bacteria," Vaccine, vol. 28, no. 50, pp. 8036-8038, 2010.

[22] I. I. Ivanov, R. D. L. Frutos, N. Manel et al., "Specific microbiota direct the differentiation of IL-17-producing Thelper cells in the mucosa of the small intestine," Cell Host and Microbe, vol. 4, no. 4, pp. 337-349, 2008.

[23] C. J. Carrico, J. L. Meakins, and J. C. Marshall, "Multipleorgan-failure syndrome," Archives of Surgery, vol. 121, no. 2, pp. 196-197, 1986.

[24] J. A. Clark and C. M. Coopersmith, "Intestinal crosstalk: a new paradigm for understanding the gut as the "motor" of critical illness," Shock, vol. 28, no. 4, pp. 384-393, 2007.

[25] L. V. Hooper, T. S. Stappenbeck, C. V. Hong, and J. I. Gordon, "Angiogenins: a new class of microbicidal proteins involved in innate immunity," Nature Immunology, vol. 4, no. 3, pp. 269-273, 2003.

[26] M. Wlodarska and B. B. Finlay, "Host immune response to antibiotic perturbation of the microbiota," Mucosal Immunology, vol. 3, no. 2, pp. 100-103, 2010.
[27] M. C. Collado, M. Hernández, and Y. Sanz, "Production of bacteriocin-like inhibitory compounds by human fecal Bifidobacterium strains," Journal of Food Protection, vol. 68, no. 5, pp. 1034-1040, 2005.

[28] C. U. Duerr, N. H. Salzman, A. Dupont et al., "Control of intestinal Nod2-mediated peptidoglycan recognition by epithelium-associated lymphocytes," Mucosal Immunology, vol. 4, no. 3, pp. 325-334, 2011.

[29] J. C. Alverdy and E. B. Chang, "The re-emerging role of the intestinal microflora in critical illness and inflammation: why the gut hypothesis of sepsis syndrome will not go away," Journal of Leukocyte Biology, vol. 83, no. 3, pp. 461-466, 2008.

[30] M. Giuliano, M. Barza, N. V. Jacobus, and S. L. Gorbach, "Effect of broad-spectrum parenteral antibiotics on composition of intestinal microflora of humans," Antimicrobial Agents and Chemotherapy, vol. 31, no. 2, pp. 202-206, 1987.

[31] Å. Sullivan, C. Edlund, and C. E. Nord, "Effect of antimicrobial agents on the ecological balance of human microflora," The Lancet Infectious Diseases, vol. 1, no. 2, pp. 101-114, 2001.

[32] W. A. Krueger, G. Ruckdeschel, and K. Unertl, "Influence of intravenously administered ciprofloxacin on aerobic intestinal microflora and fecal drug levels when administered simultaneously with sucralfate," Antimicrobial Agents and Chemotherapy, vol. 41, no. 8, pp. 1725-1730, 1997.

[33] L. N. Diebel, D. M. Liberati, C. A. Diglio, S. A. Dulchavsky, and W. J. Brown, "Synergistic effects of Candida and Escherichia coil on gut barrier function," Journal of Trauma, vol. 47, no. 6, pp. 1045-1050, 1999.

[34] K. Shimizu, H. Ogura, M. Goto et al., "Altered gut flora and environment in patients with severe SIRS," Journal of Trauma, vol. 60, no. 1, pp. 126-133, 2006.

[35] K. Shimizu, H. Ogura, T. Hamasaki et al., "Altered gut flora are associated with septic complications and death in critically Ill patients with systemic inflammatory response syndrome," Digestive Diseases and Sciences, pp. 1-7, 2010.

[36] X. Wang, R. Andersson, V. Soltesz, P. Leveau, and I. Ihse, “Gut origin sepsis, macrophage function, and oxygen extraction associated with acute pancreatitis in the rat," World Journal of Surgery, vol. 20, no. 3, pp. 299-308, 1996.

[37] S. M. Schneider, P. le Gall, F. Girard-Pipau et al., "Total artificial nutrition is associated with major changes in the fecal flora," European Journal of Nutrition, vol. 39, no. 6, pp. 248-255, 2000.

[38] M. M. Kendall and V. Sperandio, "Quorum sensing by enteric pathogens," Current Opinion in Gastroenterology, vol. 23, no. 1, pp. 10-15, 2007.

[39] O. Zaborina, F. Lepine, G. Xiao et al., "Dynorphin activates quorum sensing quinolone signaling in Pseudomonas aeruginosa," PLoS Pathogens, vol. 3, no. 3, p. e35, 2007.

[40] D. G. Souza, A. T. Vieira, A. C. Soares et al., "The essential role of the intestinal microbiota in facilitating acute inflammatory responses," Journal of Immunology, vol. 173, no. 6, pp. 4137-4146, 2004.

[41] F. J. Ferraro, B. F. Rush, G. T. Simonian et al., "A comparison of survival at different degrees of hemorrhagic shock in germ-free and germ-bearing rats," Shock, vol. 4, no. 2, pp. 117-120, 1995.

[42] J. C. Alverdy, R. S. Laughlin, and L. Wu, "Influence of the critically ill state on host-pathogen interactions within the intestine: gut-derived sepsis redefined," Critical Care Medicine, vol. 31, no. 2, pp. 598-607, 2003. 
[43] K. Madsen, "Probiotics in critically ill patients," Journal of Clinical Gastroenterology, vol. 42, supplement 3, part 1, pp. S116-S118, 2008.

[44] A. Ohata, M. Usami, and M. Miyoshi, "Short-chain fatty acids alter tight junction permeability in intestinal monolayer cells via lipoxygenase activation," Nutrition, vol. 21, no. 7-8, pp. 838-847, 2005.

[45] N. B. V. Paassen, A. Vincent, P. J. Puiman et al., "The regulation of intestinal mucin MUC2 expression by shortchain fatty acids: implications for epithelial protection," Biochemical Journal, vol. 420, no. 2, pp. 211-219, 2009.

[46] H. Ren, M. W. Musch, K. Kojima, D. Boone, A. Ma, and E. B. Chang, "Short-chain fatty acids induce intestinal epithelial heat shock protein 25 expression in rats and EIC 18 cells," Gastroenterology, vol. 121, no. 3, pp. 631-639, 2001.

[47] L. E. M. Willemsen, M. A. Koetsier, S. J. H. van Deventer, and E. A. F. van Tol, "Short chain fatty acids stimulate epithelial mucin 2 expression through differential effects on prostaglandin E1 and E2 production by intestinal myofibroblasts," Gut, vol. 52, no. 10, pp. 1442-1447, 2003.

[48] K. A. Tappenden, A. B. R. Thomson, G. E. Wild, and M. I. Mcburney, "Short-chain fatty acids increase proglucagon and ornithine decarboxylase messenger RNAs after intestinal resection in rats," Journal of Parenteral and Enteral Nutrition, vol. 20, no. 5, pp. 357-362, 1996.

[49] P. D. Cani, S. Possemiers, T. van de Wiele et al., "Changes in gut microbiota control inflammation in obese mice through a mechanism involving GLP-2-driven improvement of gut permeability," Gut, vol. 58, no. 8, pp. 1091-1103, 2009.

[50] M. Fujiya, M. W. Musch, Y. Nakagawa et al., "The bacillus subtilis quorum-sensing molecule CSF contributes to intestinal homeostasis via OCTN2, a host cell membrane transporter," Cell Host and Microbe, vol. 1, no. 4, pp. 299-308, 2007.

[51] C. M. Coopersmith, P. E. Stromberg, C. G. Davis et al., "Sepsis from Pseudomonas aeruginosa pneumonia decreases intestinal proliferation and induces gut epithelial cell cycle arrest," Critical Care Medicine, vol. 31, no. 6, pp. 1630-1637, 2003.

[52] C. M. Coopersmith, P. E. Stromberg, W. M. Dunne et al., "Inhibition of intestinal epithelial apoptosis and survival in a murine model of pneumonia-induced sepsis," Journal of the American Medical Association, vol. 287, no. 13, pp. 17161721, 2002.

[53] K. D. Husain, P. E. Stromberg, P. Javadi et al., "Bcl-2 inhibits gut epithelial apoptosis induced by acute lung injury in mice but has no effect on survival," Shock, vol. 20, no. 5, pp. 437$443,2003$.

[54] G. Andonegui, K. Goring, D. Liu, D. M. McCafferty, and B. W. Winston, "Characterization of S. pneumoniae pneumonia-induced multiple organ dysfunction syndrome: an experimental mouse model of gram-positive sepsis," Shock, vol. 31, no. 4, pp. 423-428, 2009.

[55] T. Schreiber, P. E. Swanson, K. C. Chang et al., "Both gram-negative and gram-positive experimental pneumonia induce profound lymphocyte but not respiratory epithelial cell apoptosis," Shock, vol. 26, no. 3, pp. 271-276, 2006.

[56] J. Mallegol, G. van Niel, and M. Heyman, "Phenotypic and functional characterization of intestinal epithelial exosomes," Blood Cells, Molecules, and Diseases, vol. 35, no. 1, pp. 11-16, 2005.

[57] Y. van de Wal, N. Corazza, M. Allez et al., "Delineation of a CD1d-restricted antigen presentation pathway associated with human and mouse intestinal epithelial cells," Gastroenterology, vol. 124, no. 5, pp. 1420-1431, 2003.

[58] A. D. Christ and R. S. Blumberg, "The intestinal epithelial cell: immunological aspects," Springer Seminars in Immunopathology, vol. 18, no. 4, pp. 449-461, 1997.

[59] C. S. Chung, L. Watkins, A. Funches, J. Lomas-Neira, W. G. Cioffi, and A. Ayala, "Deficiency of gammadelta T lymphocytes contributes to mortality and immunosuppression in sepsis," American Journal of Physiology-Regulatory Integrative and Comparative Physiology, vol. 291, no. 5, pp. R1338-R1343, 2006.

[60] Y. Chen, K. Chou, E. Fuchs, W. L. Havran, and R. Boismenu, "Protection of the intestinal mucosa by intraepithelial $\gamma \delta \mathrm{T}$ cells," Proceedings of the National Academy of Sciences of the United States of America, vol. 99, no. 22, pp. 14338-14343, 2002.

[61] C. S. Chung, Y. X. Xu, W. Wang, I. H. Chaudry, and A. Ayala, "Is Fas ligand or endotoxin responsible for mucosal lymphocyte apoptosis in sepsis?" Archives of Surgery, vol. 133, no. 11, pp. 1213-1220, 1998.

[62] K. Fukatsu, S. Sakamoto, E. Hara et al., "Gut ischemiareperfusion affects gut mucosal immunity: a possible mechanism for infectious complications after severe surgical insults," Critical Care Medicine, vol. 34, no. 1, pp. 182-187, 2006.

[63] C. S. Chung, W. Wang, I. H. Chaudry, and A. Ayala, "Increased apoptosis in lamina propria B cells during polymicrobial sepsis is FasL but not endotoxin mediated," American Journal of Physiology-Gastrointestinal and Liver Physiology, vol. 280, no. 5, pp. G812-G818, 2001.

[64] S. U. Sheth, Q. Lu, K. Twelker et al., "Intestinal mucus layer preservation in female rats attenuates gut injury after trauma-hemorrhagic shock," Journal of Trauma, vol. 68, no. 2, pp. 279-287, 2010.

[65] Q. Lu, D. Z. Xu, S. Sharpe et al., "The anatomic sites of disruption of the mucus layer directly correlate with areas of Trauma/Hemorrhagic shock-induced gut injury," Journal of Trauma, 2010.

[66] B. Rupani, F. J. Caputo, A. C. Watkins et al., "Relationship between disruption of the unstirred mucus layer and intestinal restitution in loss of gut barrier function after trauma hemorrhagic shock," Surgery, vol. 141, no. 4, pp. 481-489, 2007.

[67] M. Z. L. Y. Yiang, T. E. Zhou, Z. F. Yang, L. Q. Wen, and J. X. Chang, "Changes of the immunological barrier of intestinal mucosa in rats with sepsis," World Journal of Emergency Medicine, vol. 1, no. 2, pp. 138-143, 2010.

[68] D. H. Chung, B. M. Evers, C. M. Townsend et al., "Role of polyamine biosynthesis during gut mucosal adaptation after burn injury," American Journal of Surgery, vol. 165, no. 1, pp. 144-149, 1993.

[69] C. Liu, A. Li, Y. B. Weng, M. L. Duan, B. E. Wang, and S. W. Zhang, "Changes in intestinal mucosal immune barrier in rats with endotoxemia," World Journal of Gastroenterology, vol. 15, no. 46, pp. 5843-5850, 2009.

[70] J. Fan, Y. Xie, X. Li et al., "The influence of Peyer's patch apoptosis on intestinal mucosal immunity in burned mice," Burns, vol. 35, no. 5, pp. 687-694, 2009.

[71] H. B. Coutinho, T. I. Robalinho, V. B. Coutinho et al., "Intra-abdominal sepsis: an immunocytochemical study of the small intestine mucosa," Journal of Clinical Pathology, vol. 50, no. 4, pp. 294-298, 1997.

[72] R. T. Hurt, P. J. Matheson, M. P. Mays, and R. N. Garrison, "Immune-enhancing diet and cytokine expression during 
chronic sepsis: an immune-enhancing diet containing Larginine, fish oil, and RNA fragments promotes intestinal cytokine expression during chronic sepsis in rats," Journal of Gastrointestinal Surgery, vol. 10, no. 1, pp. 46-53, 2006.

[73] W. A. Altemeier and S. E. Sinclair, "Hyperoxia in the intensive care unit: why more is not always better," Current Opinion in Critical Care, vol. 13, no. 1, pp. 73-78, 2007.

[74] A. E. Baylor, L. N. Diebel, D. M. Liberati, S. A. Dulchavsky, C. A. Diglio, and W. J. Brown, "The effects of varying oxygen conditions and immunoglobulin A on barrier defense to bacterial invasion," American Surgeon, vol. 69, no. 3, pp. 231237, 2003.

[75] L. N. Diebel, D. M. Liberati, S. A. Dulchavsky, C. A. Diglio, and W. J. Brown, "Synergistic effect of hyperoxia and immunoglobulin A on mucosal barrier defense," Journal of Trauma, vol. 46, no. 3, pp. 374-378, 1999.

[76] M. Bruewer, A. Luegering, T. Kucharzik et al., "Proinflammatory cytokines disrupt epithelial barrier function by apoptosis-independent mechanisms," Journal of Immunology, vol. 171, no. 11, pp. 6164-6172, 2003.

[77] P. L. Sappington, R. Yang, H. Yang, K. J. Tracey, R. L. Delude, and M. P. Fink, "HMGB1 B box increases the permeability of Caco-2 enterocytic monolayers and impairs intestinal barrier function in mice," Gastroenterology, vol. 123, no. 3, pp. 790$802,2002$.

[78] H. J. Epple, T. Schneider, H. Troeger et al., "Impairment of the intestinal barrier is evident in untreated but absent in suppressively treated HIV-infected patients," Gut, vol. 58, no. 2, pp. 220-227, 2009.

[79] K. G. Raman, P. L. Sappington, R. Yang et al., "The role of RAGE in the pathogenesis of intestinal barrier dysfunction after hemorrhagic shock," American Journal of PhysiologyGastrointestinal and Liver Physiology, vol. 291, no. 4, pp. G556-G565, 2006.

[80] J. K. Roche, C. A. P. Martins, R. Cosme, R. Fayer, and R. L. Guerrant, "Transforming growth factor $\beta 1$ ameliorates intestinal epithelial barrier disruption by Cryptosporidium parvum in vitro in the absence of mucosal T lymphocytes," Infection and Immunity, vol. 68, no. 10, pp. 5635-5644, 2000.

[81] K. L. Madsen, S. A. Lewis, M. M. Tavernini, J. Hibbard, and R. N. Fedorak, "Interleukin 10 prevents cytokine-induced disruption of T84 monolayer barrier integrity and limits chloride secretion," Gastroenterology, vol. 113, no. 1, pp. 151159, 1997.

[82] E. Clark, C. Hoare, J. Tanianis-Hughes, G. L. Carlson, and G. Warhurst, "Interferon $\gamma$ induces translocation of commensal Escherichia coli across gut epithelial cells via a lipid raftmediated process," Gastroenterology, vol. 128, no. 5, pp. 1258-1267, 2005.

[83] K. Katada, A. Bihari, A. Badhwar et al., "Hindlimb ischemia/reperfusion-induced remote injury to the small intestine: role of inducible nitric-oxide synthase-derived nitric oxide," Journal of Pharmacology and Experimental Therapeutics, vol. 329, no. 3, pp. 919-927, 2009.

[84] X. Han, M. P. Fink, R. Yang, and R. L. Delude, "Increased iNOS activity is essential for intestinal epithelial tight junction dysfunction in endotoxemic mice," Shock, vol. 21, no. 3, pp. 261-270, 2004.

[85] G. W. Hunninghake, K. C. Doerschug, A. B. Nymon, G. A. Schmidt, D. K. Meyerholz, and A. Ashare, "Insulinlike growth factor-1 levels contribute to the development of bacterial translocation in sepsis," American Journal of Respiratory and Critical Care Medicine, vol. 182, no. 4, pp. 517-525, 2010.
[86] J. Alverdy and E. Aoys, "The effect of glucocorticoid administration on bacterial translocation: evidence for an acquired mucosal immunodeficient state," Annals of Surgery, vol. 214, no. 6, pp. 719-723, 1991.

[87] L. Gianotti, J. W. Alexander, R. Fukushima, and T. Pyles, "Steroid therapy can modulate gut barrier function, host defense, and survival in thermally injured mice," Journal of Surgical Research, vol. 62, no. 1, pp. 53-58, 1996.

[88] T. Kawasaki, C. Kawasaki, T. Sata, and I. H. Chaudry, "Lidocaine suppresses mouse Peyer's Patch T cell functions and induces bacterial translocation," Surgery, vol. 149, no. 1, pp. 106-113, 2011.

[89] J. Sun, L. Wang, J. Shen, Z. Wang, and Y. Qian, "Effect of propofol on mucous permeability and inflammatory mediators expression in the intestine following traumatic brain injury in rats," Cytokine, vol. 40, no. 2, pp. 151-156, 2007.

[90] J. Österberg, M. Ljungdahl, and U. Haglund, "Influence of cyclooxygenase inhibitors on gut immune cell distribution and apoptosis rate in experimental sepsis," Shock, vol. 25, no. 2, pp. 147-154, 2006.

[91] B. Li, Y. M. Li, X. Li et al., "COX-2 inhibition improves immune system homeostasis and decreases liver damage in septic rats," Journal of Surgical Research, vol. 157, no. 1, pp. 43-47, 2009.

[92] V. Due, J. Bonde, K. Espersen, T. H. Jensen, and A. Perner, "Lactic acidosis in the rectal lumen of patients with septic shock measured by luminal equilibrium dialysis," British Journal of Anaesthesia, vol. 89, no. 6, pp. 919-922, 2002.

[93] Q. Wang, J. J. Wang, S. Boyce, J. E. Fischer, and P. O. Hasselgren, "Endotoxemia and IL-1 $\beta$ stimulate mucosal IL6 production in different parts of the gastrointestinal tract," Journal of Surgical Research, vol. 76, no. 1, pp. 27-31, 1998.

[94] J. Unsinger, H. Kazama, J. S. McDonough, T. S. Griffith, R. S. Hotchkiss, and T. A. Ferguson, "Sepsis-induced apoptosis leads to active suppression of delayed-type hypersensitivity by $\mathrm{CD} 8+$ regulatory $\mathrm{T}$ cells through a TRAIL-dependent mechanism," Journal of Immunology, vol. 184, no. 12, pp. 6766-6772, 2010.

[95] F. A. Moore, E. E. Moore, R. Poggetti et al., "Gut bacterial translocation via the portal vein: a clinical perspective with major torso trauma," Journal of Trauma, vol. 31, no. 5, pp. 629-638, 1991.

[96] D. J. Koo, M. Zhou, D. Jackman et al., "Is gut the major source of proinflammatory cytokine release during polymicrobial sepsis?" Biochimica et Biophysica Acta, vol. 1454, no. 3, pp. 289-295, 1999.

[97] E. A. Deitch, "Gut lymph and lymphatics: a source of factors leading to organ injury and dysfunction," Annals of the New York Academy of Sciences, vol. 1207, supplement 1, pp. E103E111, 2010.

[98] S. Yang, D. J. Koo, M. Zhou, I. H. Chaudry, and P. Wang, "Gut-derived norepinephrine plays a critical role in producing hepatocellular dysfunction during early sepsis," American Journal of Physiology-Gastrointestinal and Liver Physiology, vol. 279, no. 6, pp. G1274-G1281, 2000.

[99] B. E. Wildhaber, H. Yang, A. U. Spencer, R. A. Drongowski, and D. H. Teitelbaum, "Lack of enteral nutrition-effects on the intestinal immune system," Journal of Surgical Research, vol. 123, no. 1, pp. 8-16, 2005.

[100] I. Kiristioglu, P. Antony, Y. Fan et al., "Total parenteral nutrition-associated changes in mouse intestinal intraepithelial lymphocytes," Digestive Diseases and Sciences, vol. 47, no. 5, pp. 1147-1157, 2002. 
[101] X. Sun, H. Yang, K. Nose et al., "Decline in intestinal mucosal IL-10 expression and decreased intestinal barrier function in a mouse model of total parenteral nutrition," American Journal of Physiology-Gastrointestinal and Liver Physiology, vol. 294, no. 1, pp. G139-G147, 2007.

[102] H. Yang, I. Kiristioglu, Y. Fan et al., "Interferon-gamma expression by intraepithelial lymphocytes results in a loss of epithelial barrier function in a mouse model of total parenteral nutrition," Annals of Surgery, vol. 236, no. 2, pp. 226-234, 2002.

[103] G. Spaeth, T. Gottwald, R. D. Specian, M. R. Mainous, R. D. Berg, and E. A. Deitch, "Secretory immunoglobulin A, intestinal mucin, and mucosal permeability in nutritionally induced bacterial translocation in rats," Annals of Surgery, vol. 220, no. 6, pp. 798-808, 1994.

[104] J. Li, B. K. King, P. G. Janu, K. B. Renegar, and K. A. Kudsk, "Glycyl-L-glutamine-enriched total parenteral nutrition maintains small intestine gut-associated lymphoid tissue and upper respiratory tract immunity," Journal of Parenteral and Enteral Nutrition, vol. 22, no. 1, pp. 31-36, 1998.

[105] T. Ikeda, K. Hiromatsu, M. Hotokezaka, and K. Chijiiwa, "Up-regulation of intestinal toll-like receptors and cytokines expressions change after TPN administration and a lack of enteral feeding," Journal of Surgical Research, vol. 160, no. 2, pp. 244-252, 2010.

[106] H. Yang, X. Sun, E. Q. Haxhija, and D. H. Teitelbaum, "Intestinal epithelial cell-derived interleukin-7: a mechanism for the alteration of intraepithelial lymphocytes in a mouse model of total parenteral nutrition," American Journal of Physiology_Gastrointestinal and Liver Physiology, vol. 292, no. 1, pp. G84-G91, 2007.

[107] H. Yang, D. L. Gumucio, and D. H. Teitelbaum, "Intestinal specific overexpression of interleukin-7 attenuates the alternation of intestinal intraepithelial lymphocytes after total parenteral nutrition administration," Annals of Surgery, vol. 248, no. 5, pp. 849-856, 2008.

[108] K. Nose, H. Yang, X. Sun et al., "Glutamine prevents total parenteral nutrition-associated changes to intraepithelial lymphocyte phenotype and function: a potential mechanism for the preservation of epithelial barrier function," Journal of Interferon and Cytokine Research, vol. 30, no. 2, pp. 67-79, 2010.

[109] K. A. Kudsk, Y. Wu, K. Fukatsu et al., "Glutamine-enriched total parenteral nutrition maintains intestinal interleukin-4 and mucosal immunoglobulin A levels," Journal of Parenteral and Enteral Nutrition, vol. 24, no. 5, pp. 270-274, 2000.

[110] K. Fukatsu, K. A. Kudsk, B. L. Zarzaur, Y. Wu, M. K. Hanna, and R. C. DeWitt, "TPN decreases IL-4 and IL-10 mRNA expression in lipopolysaccharide stimulated intestinal lamina propria cells but glutamine supplementation preserves the expression," Shock, vol. 15, no. 4, pp. 318-322, 2001.

[111] Y. N. Lai, S. L. Yeh, M. T. Lin, H. F. Shang, C. L. Yeh, and W. J. Chen, "Glutamine supplementation enhances mucosal immunity in rats with gut-derived sepsis," Nutrition, vol. 20, no. 3, pp. 286-291, 2004.

[112] L. D. Erickson, T. M. Foy, and T. J. Waldschmidt, "Murine B1 B cells require IL-5 for optimal T cell-dependent activation," Journal of Immunology, vol. 166, no. 3, pp. 1531-1539, 2001.

[113] N. Baumgarth, J. W. Tung, and L. A. Herzenberg, "Inherent specificities in natural antibodies: a key to immune defense against pathogen invasion," Springer Seminars in Immunopathology, vol. 26, no. 4, pp. 347-362, 2005.
[114] K. Ritter, A. Fudickar, N. Heine, and R. Thomssen, "Autoantibodies with a protective function: polyreactive antibodies against alkaline phosphatase in bacterial infections," Medical Microbiology and Immunology, vol. 186, no. 2-3, pp. 109-113, 1997.

[115] D. J. Drucker, "Biologic actions and therapeutic potential of the proglucagon-derived peptides," Nature Clinical Practice. Endocrinology \& metabolism, vol. 1, no. 1, pp. 22-31, 2005.

[116] K. A. Tappenden and M. I. McBurney, "Systemic short-chain fatty acids rapidly alter gastrointestinal structure, function, and expression of early response genes," Digestive Diseases and Sciences, vol. 43, no. 7, pp. 1526-1536, 1998.

[117] R. P. Dellinger, M. M. Levy, J. M. Carlet et al., "Surviving sepsis campaign: international guidelines for management of severe sepsis and septic shock: 2008," Critical Care Medicine, vol. 36, no. 1, pp. 296-327, 2008.

[118] J. G. Mogilner, I. Srugo, M. Lurie et al., "Effect of probiotics on intestinal regrowth and bacterial translocation after massive small bowel resection in a rat," Journal of Pediatric Surgery, vol. 42, no. 8, pp. 1365-1371, 2007.

[119] H. F. Bu, X. Wang, Y. Q. Zhu et al., "Lysozyme-modified probiotic components protect rats against polymicrobial sepsis: role of macrophages and cathelicidin-related innate immunity," Journal of Immunology, vol. 177, no. 12, pp. 8767-8776, 2006.

[120] P. J. Watkinson, V. S. Barber, P. Dark, and J. D. Young, “The use of pre- pro- and synbiotics in adult intensive care unit patients: systematic review," Clinical Nutrition, vol. 26, no. 2, pp. 182-192, 2007.

[121] D. Barraud, C. Blard, F. Hein et al., "Probiotics in the critically ill patient: a double blind, randomized, placebocontrolled trial," Intensive Care Medicine, vol. 36, no. 9, pp. 1540-1547, 2010.

[122] G. Bertolini, G. Iapichino, D. Radrizzani et al., "Early enteral immunonutrition in patients with severe sepsis: results of an interim analysis of a randomized multicentre clinical trial," Intensive Care Medicine, vol. 29, no. 5, pp. 834-840, 2003.

[123] M. H. Land, K. Rouster-Stevens, C. R. Woods, M. L. Cannon, J. Cnota, and A. K. Shetty, "Lactobacillus sepsis associated with probiotic therapy," Pediatrics, vol. 115, no. 1, pp. 178181, 2005. 


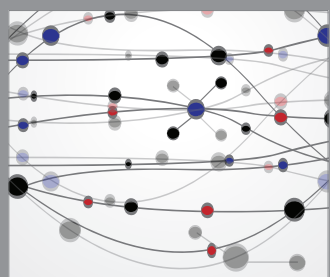

The Scientific World Journal
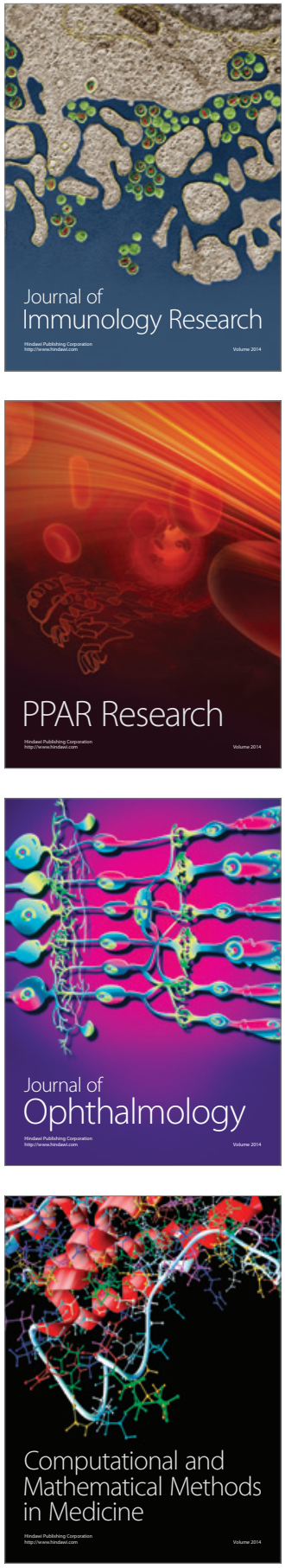

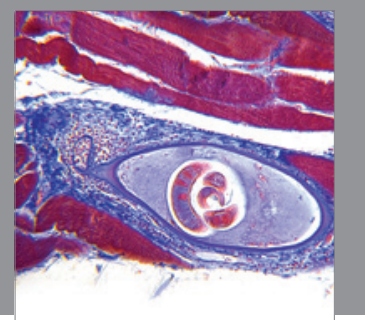

Gastroenterology

Research and Practice
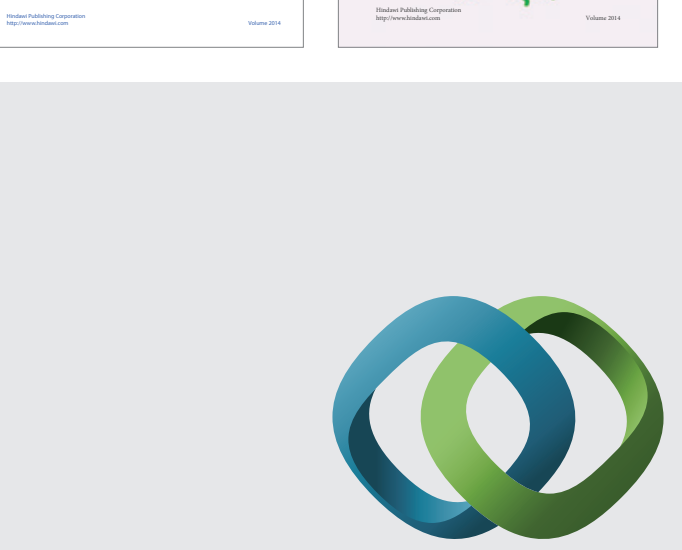

\section{Hindawi}

Submit your manuscripts at

http://www.hindawi.com
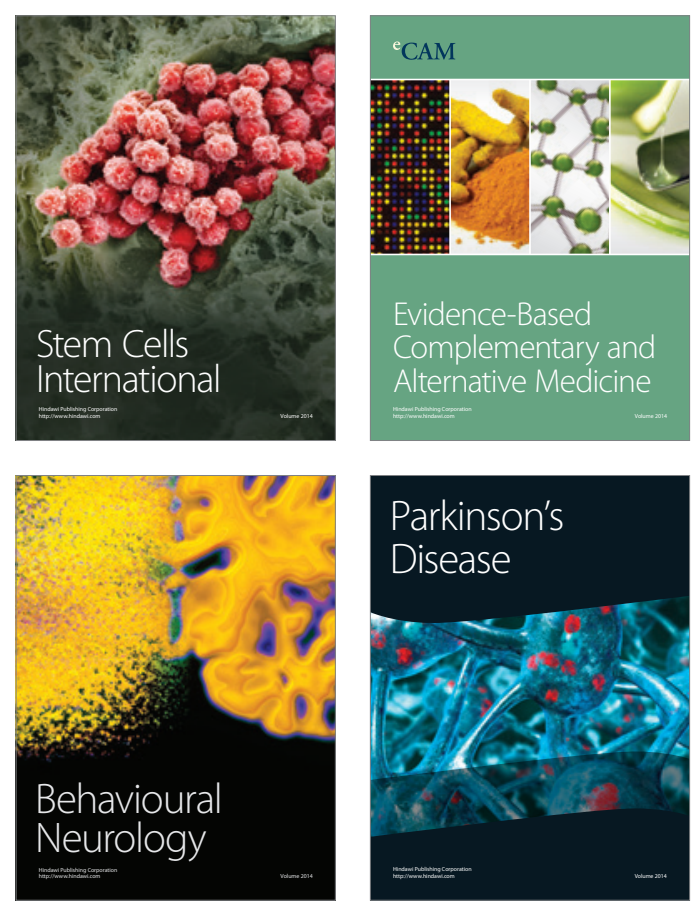

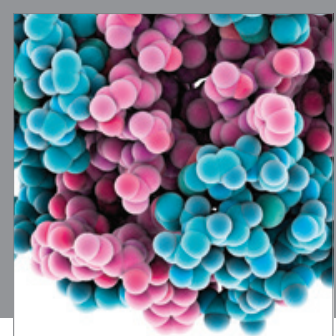

Journal of
Diabetes Research

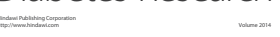

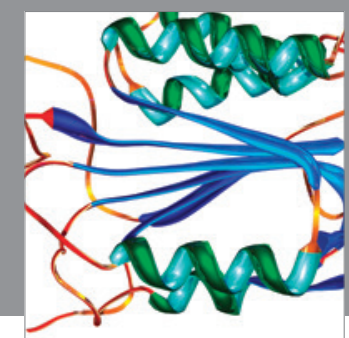

Disease Markers
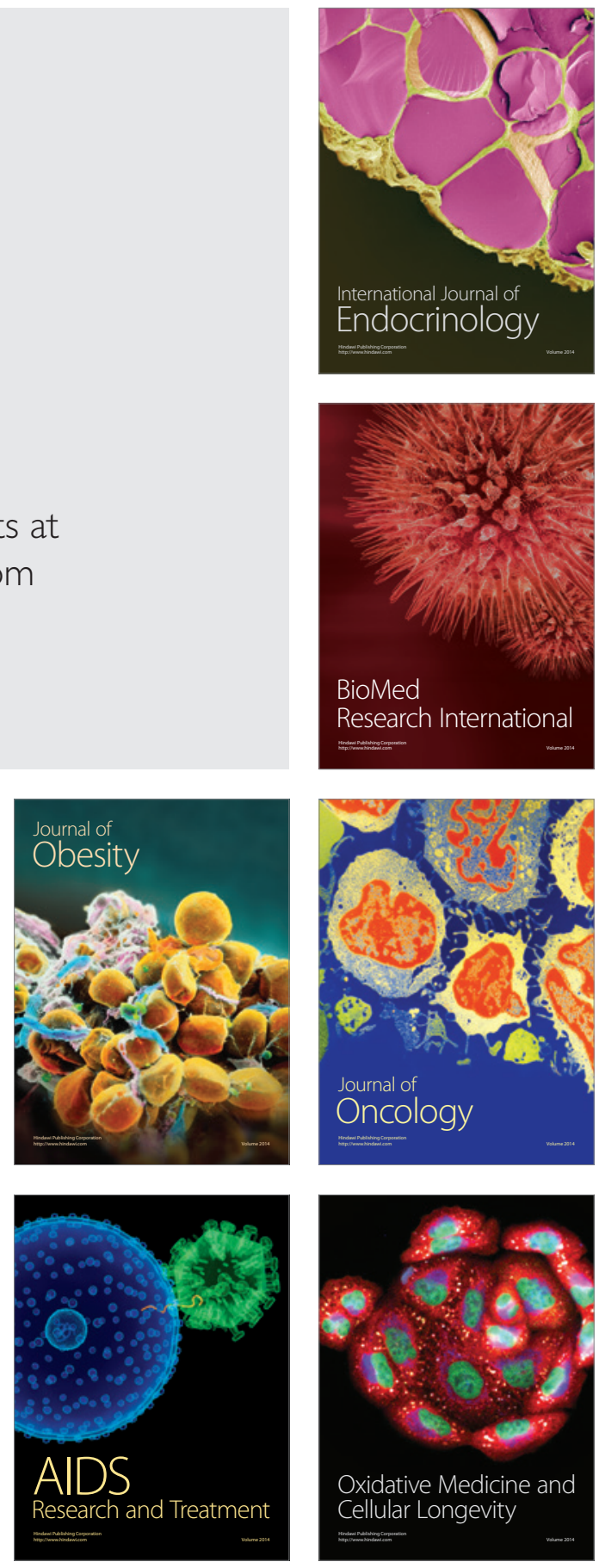